\title{
Pullulan: an advantageous natural polysaccharide excipient to formulate tablets of alendronate-loaded microparticles
}

\author{
Luana Mota Ferreira, Aline de Arce Velasquez, Scheila Rezende Schaffazick, Letícia Cruz*
}

Department of Industrial Pharmacy, Federal University of Santa Maria, Santa Maria, Brazil

\begin{abstract}
This work reports the preparation of tablets by direct compression of sodium alendronate-loaded microparticles, using pullulan as filler. The tableting properties of pullulan were compared with those of microcrystalline cellulose and lactose. Pullulan tablets showed low variations in average weight, thickness and drug content. Moreover, these tablets exhibited a higher hardness compared to the other excipients. In vitro release studies showed that only pullulan was capable to maintain gastroresistance and release properties of microparticles, due to its ability to protect particles against damage caused by compression force. Thus, pullulan was considered an advantageous excipient to prepare tableted microparticles.
\end{abstract}

Uniterms: Pullulan. Excipients. Microparticulate tablets. Sodium alendronate.

\begin{abstract}
Neste trabalho relata-se a preparação de comprimidos pela compressão direta de micropartículas contendo alendronato de sódio, utilizando o pullulan como diluente. As propriedades dos comprimidos de pullulan foram comparadas com as de comprimidos de celulose microcristalina e de lactose. Os comprimidos de pullulan mostraram baixa variação no peso médio, espessura e teor. Por outro lado, estes apresentaram altos valores de dureza comparados aos preparados com os outros excipientes. Através dos estudos de liberação in vitro pode-se observar que apenas o pullulan foi capaz de manter a gastrorresistência e as propriedades de liberação das micropartículas, o que se deve à sua capacidade de proteger as partículas do dano causado pela força de compressão. Dessa forma, o pullulan foi considerado um excipiente vantajoso para a preparação de comprimidos microparticulados.
\end{abstract}

Unitermos: Pullulan. Excipientes. Comprimidos microparticulados. Alendronato de sódio.

\section{INTRODUCTION}

Polymeric microparticles are promising carriers for oral administration of therapeutic drugs mainly due to their ability to give a more uniform distribution of the drug in the gastrointestinal tract, thus increasing bioavailability and reducing mucosal toxicity (Freiberg, Zhu, 2004; Varde, Pack, 2004). A previous study reported the development of gastroresistant microparticles made of Eudragit ${ }^{\circledR}$ S100 in order to reduce mucosal damage associated with sodium alendronate, an antiosteoporotic drug (Cruz et al., 2010). Although Eudragit ${ }^{\circledR}$ S100 microparticles can be considered a promising alternative for oral administration of sodium alendronate, microparticles are rarely used directly in their

\footnotetext{
*Correspondence: Letícia Cruz. Departamento de Farmácia Industrial, Universidade Federal de Santa Maria. Avenida Roraima, 1000, prédio 26, 97105-900 - Santa Maria - RS, Brasil. E-mail: leticiacruz@smail.ufsm.br
}

powder form, thus, the development of a final formulation is required.<smiles>NCCCC(O)(P(=O)(O)O)P(=O)(O)[18O]</smiles>

FIGURE 1 - Chemical structure of sodium alendronate.

Tablets are the most popular form of solid dosage, because they are easily dosed, produced and are stable (Jivraj, Martini, Thomson, 2000; Wening, Breitkreutz, 2011). Tablets can be divided into monolithic (single-unit 
dosage form) and multiparticulate (multiple-units dosage forms) systems. In the former, there is only one release unit in which the drug is not divided. On the other hand, in a multiparticulate system the drug is divided in subunits of release, which can be granules, pellets, minitablets or microparticles. These subunits, in turn, were compressed into tablets by direct compression using tableting excipients (Pezzini, Silva, Ferraz, 2007). However, compressing microparticles into tablets is a challenge due to the fact that the particle must withstand the compression force in order to avoid its rupture or deformation with consequent increase in dissolution rates (Torrado, Augsburger, 1994). In this sense, the selection of a suitable excipient can be considered an interesting approach to form multiple unit tablets. In general, materials that deform plastically, such as microcrystalline cellulose, give the best protective effect (Torrado, Augsburger, 1994; Beckert, Lehmann, Schmidt, 1996; Velasquez et al., 2014). Moreover, an ideal excipient should result in hard and disintegrating tablets at low compression forces and should not affect drug release (Bodmeier, 1997).

Natural polysaccharides are widely employed as pharmaceutical excipients because of their low toxicity, availability and low cost (Ngwuluka et al., 2010). Pullulan, a neutral polysaccharide of microbiological origin, has attracted much attention in the last few years in view of its potential for pharmaceutical and biomedical applications (Rekha, Sharma, 2007). This exopolysaccharide is produced from starch by Aureobasidium pullulans and is comprised of maltotriose repeating units linked by $\alpha(1 \rightarrow 6)$ bonds. Pullulan is considered a promising biomaterial mainly due to its non-toxic, biodegradable and bioadhesive properties (Cheng, Demirci, Catchmark, 2011). In the pharmaceutical field, pullulan is being used as a plasma expander and in the composition of oral care products due to its ability to form colorless, transparent and edible films. In the formulation of oral solid dosage forms, pullulan has been reported to prepare vegetarian capsule shells and act as a coating agent to prevent tablet deterioration, increase mechanical resistance, reduce cracking and color deterioration and improve gloss (Cheng, Demirci, Catchmark, 2011). Up to now, there is no report on the preparation of tableted microparticles with pullulan.

Taking all of this into account, the aim of the present study was to prepare tablets by direct compression of sodium alendronate-loaded Eudragit ${ }^{\mathbb{B}} \mathrm{S} 100$ microparticles using pullulan as a filler and to evaluate the gastroresistance, drug release profile and morphology of the microparticles after compression. The tableting properties of pullulan were compared with those of two widely used excipients, microcrystalline cellulose and lactose.

\section{MATERIAL AND METHODS}

\section{Material}

Monosodium alendronate trihydrate was purchased from Pharma Nostra (São Paulo, Brazil). Pullulan was generously donated by Corn Products (São Paulo, Brazil) and Eudragit ${ }^{\circledR}$ S100 (Poly(methacrylic acid-co-methyl methacrylate) 1:2) from Degussa was donated by Almapal (São Paulo, Brazil). Lactose and stearate magnesium were obtained from Henrifarma (São Paulo, Brazil). Avicel ${ }^{\circledR}$

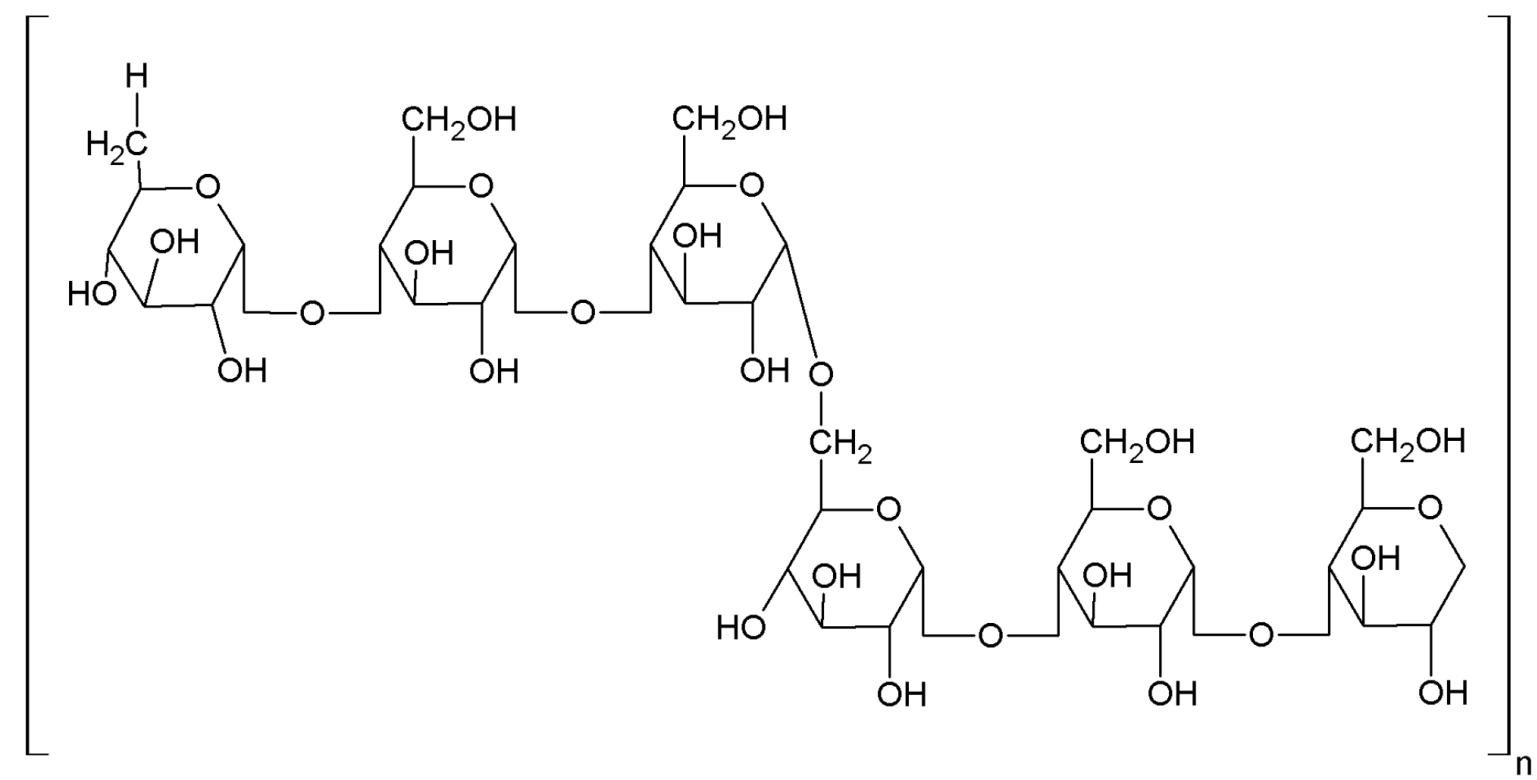

FIGURE 2 - Chemical structure of pullulan. 
PH101 (Microcrystalline cellulose) was a gift from FMC corporation (Philadelphia, USA). $o$-Phtalaldehyde was purchased from Sigma-Aldrich (São Paulo, Brazil) and 2-mercaptoethanol was acquired from Acros Organics (Geel, Belgium). All other solvents and reagents were of analytical grade and were used as received.

\section{Preparation and characterization of microparticles}

As previously described (Cruz et al., 2010), alendronate-loaded microparticles (AMP) were prepared by the spray-drying technique. Briefly, an alkaline solution $(0.05 \mathrm{~mol} / \mathrm{L} \mathrm{NaOH})$ of Eudragit ${ }^{\circledR} \mathrm{S} 100(16.0 \mathrm{~g} / \mathrm{L})$ was prepared under magnetic stirring at $50^{\circ} \mathrm{C}$. Alendronate $(4.0 \mathrm{~g} / \mathrm{L})$ was added to the solution before spray-drying (MSD 1.0, LabMaq, Brazil). Operational conditions were the following: feed rate of $0.33 \mathrm{~L} / \mathrm{h}$, air flow rate of $70 \mathrm{~nL} / \mathrm{h}$, atomizing air pressure of $3.0 \mathrm{kgf} / \mathrm{cm}$, inlet temperature of $150{ }^{\circ} \mathrm{C}$ and nozzle diameter of $1.2 \mathrm{~mm}$. The yield of the process was calculated by the ratio of the experimental weight and the sum of the weights of all components, discounting the water content.

Encapsulation efficiency was determined by spectrophotometry using $o$-phtalaldehyde (OPA) as a derivatizing agent (Cruz et al., 2009). A stock standard solution of alendronate was prepared by accurately weighing and dissolving $12.5 \mathrm{mg}$ of the drug in $25 \mathrm{~mL}$ of $0.2 \mathrm{~mol} / \mathrm{L}$ $\mathrm{NaOH}$ in a volumetric flask. The derivatizing solution consisted of $50 \mathrm{mg}$ of OPA and $250 \mu \mathrm{L}$ of mercaptoethanol diluted with $50 \mathrm{~mL}$ of $0.05 \mathrm{~mol} / \mathrm{L} \mathrm{NaOH}$ in a volumetric flask. Six standard solutions with different concentrations of alendronate $(10-60 \mu \mathrm{g} / \mathrm{mL})$ were then prepared by adding aliquots of the stock alendronate solution and derivatizing them with $4 \mathrm{~mL}$ of the OPA reagent. The volume was completed to $50 \mathrm{~mL}$ with $0.2 \mathrm{~mol} / \mathrm{L} \mathrm{NaOH}$. The absorbances were measured at $333 \mathrm{~nm}$.

Particle sizes and size distribution (Span) were evaluated by laser diffraction using a Mastersizer 2000 device (Malvern, United Kingdom) equipped with a Sirocco dry disperser at dispersing pressure of 1 bar.

Moisture content was assayed using an infrared drying equipment IV 2500 (Gehaka, Brazil) kept at $115^{\circ} \mathrm{C}$ until constant weight.

\section{Preparation and characterization of tableted microparticles}

Tablets with theoretical mean weight of $750 \mathrm{mg}$ were prepared by direct compression of AMP and excipients (Sinka et al., 2009). Firstly, an amount of microparticles corresponding to $91.35 \mathrm{mg}$ of alendronate was mixed with pullulan (or microcrystalline cellulose or lactose) and the lubricant (magnesium stearate) in a glass mortar. The percent composition was $77 \%$ AMP, $22.25 \%$ filler, and $0.75 \%$ lubricant. The formulations were named as T1, T2 and $\mathrm{T} 3$ when pullulan, microcrystalline cellulose or lactose were used as diluents, respectively.

Subsequently, an exact amount of the powder mixture was filled in a die using a little pressure. Hydraulic pressure $\left(300 \mathrm{kgf} / \mathrm{cm}^{2}\right)$ was then used to form flat faced tablets of $13 \mathrm{~mm}$ diameter and $4 \mathrm{~mm}$ thickness in an eccentric compression machine (Neuberger Press, Brazil). The weight variation was determined by weighing individually 10 tablets in an analytical balance AY220 (Shimadzu, Japan).

Thickness was evaluated using a manual caliper $(n=10)$. The value of mean hardness $(n=10)$ was obtained by using a portable hardness tester (Off Tec Galileo, Brazil).

To determine the uniformity of content $(n=3)$, each tablet was pulverized in a glass mortar and the drug was extracted by diluting $(0.2 \mathrm{~mol} / \mathrm{L} \mathrm{NaOH} ; 50 \mathrm{~mL})$ and sonicating (30 $\mathrm{min})$ the powder in a volumetric flask. After filtration and dilution $(0.2 \mathrm{~mol} / \mathrm{L} \mathrm{NaOH} ; 50 \mathrm{~mL})$, an aliquot was assayed spectrophotometrically at $333 \mathrm{~nm}$ after derivatization with OPA as described above.

For in vitro release profiles $(n=3)$, experiments were carried out in a dissolution apparatus PTW II (Pharma Test, Brazil): basket, rotation speed of $100 \mathrm{rpm}$ at $37^{\circ} \mathrm{C}$ (Cruz et al., 2010). Gastroresistance was evaluated during 120 minutes in $900 \mathrm{~mL} 0.1 \mathrm{~mol} / \mathrm{L} \mathrm{HCl}(\mathrm{pH} 1.2)$. In its turn, the dissolution test was performed in $900 \mathrm{~mL}$ phosphate buffer (pH 6.8) during 240 minutes. At specified time intervals, $1 \mathrm{~mL}$ was withdrawn and immediately replaced by the medium. The percent of alendronate released was assayed spectrophotometrically after dervatization $(\lambda=333 \mathrm{~nm})$ as described above.

Drug release profiles were analyzed by the first order equation, $Q_{t} / Q_{\infty}=1-\left[e^{-k t}\right]$, and the KorsmeyerPeppas model, $Q / Q_{\infty}=a . t^{n}$. In these equations, $Q / Q_{\infty}$ is the fractional drug release, $k$ is the rate constant, $a$ is a constant incorporating structural and geometric characteristics of the carrier, and $n$ is the release exponent, indicative of the drug release mechanism. For systems presenting spherical geometry, $n=0.43$ corresponds to Fickian diffusion, $n$ values between 0.43 and 0.85 imply anomalous transport, while $n \geq 0.85$ indicates case II transport (Korsmeyer et al., 1983).

SEM microphotographs of tablet cross-sections were obtained by breaking the units into half. The fractured parts of the tablet were gold sputtered (Desk II 
Gold Sputter, Denton Vacuum, USA) and subsequently analyzed using an accelerating voltage of $10 \mathrm{kv}$ (Scanning microscope JSM-6360, Jeol, Japan).

\section{Statistical analysis}

The data were analyzed by one way or two way analysis of variance (ANOVA). The Tukey test was used for multiple comparisons. A p-value $<0.05$ was considered to be statistically significant (GraphPad Prism software, U.S.A).

\section{RESULTS AND DISCUSSION}

AMP formulation was obtained with a yield of $43.19 \pm 1.13 \%$, encapsulation efficiency of $87.75 \pm 0.31 \%$, moisture content of $5.9 \%$, mean diameter of $3.65 \mu \mathrm{m}$ with narrow size distribution (Span of 1.43). The formed microparticles were tableted by direct compression using pullulan (formulation T1). For comparison, tableted microparticles were also produced with traditional fillers, such as microcrystalline cellulose (formulation T2) and lactose (formulation T3) due to their excellent properties as filler-binders (Jivraj, Martini, Thomson, 2000). The properties of tablets containing AMP are shown in Table I.

Tablets prepared with pullulan (T1) showed low variations in the characteristics studied, as observed for the formulations T2 and T3, which means that the compression process was consistent. Comparing the three tablet formulations, there were no significant differences in average weight and thickness $(\mathrm{p}>0.05)$. On the other hand, hardness, which corresponds to the tablet breaking force, was significantly different among all formulations $(p<0.05)$. Existing studies in the literature show that the use of different types of diluents may influence the hardness of tablets, due to compaction properties of each raw material (Holgado et al., 1995). The results clearly show that pullulan has excellent binding properties upon compaction, producing more cohesive and compact tablets in comparison to the other adjuvants evaluated (microcrystalline cellulose and lactose) by employing the same proportion in the formulation and applying the same compression force. It should be noted that in a previous test, alendronate-loaded Eudragit ${ }^{\circledR}$ S100 microparticles, without any excipient, were not able to form tablets by direct compression (data not showed) due to their poor binding properties. Thus, pullulan imparts suitable hardness to the tablets without addition of a specific binder in the formulation, probably as a result of its adhesive and cohesive properties. As regards uniformity of content, the tablets prepared with pullulan had also a content percent close to the theoretical value (Table I).

With respect to the evaluation of gastroresistance, tableted AMP was submitted to a simulated gastric fluid (Figure 3). Within $120 \mathrm{~min}, 24.5 \pm 0.72 \%$ and $27.6 \pm 1.18 \%$ of alendronate were released from microcrystalline cellulose and lactose tablets, respectively, whereas only $6.7 \pm 0.30 \%$ of the drug was released from pullulan tablets at the same time. In a previous study (Cruz et al., 2010), it has been shown that about $5 \%$ of alendronate was released from Eudragit ${ }^{\circledR}$ S100 microparticles under the same experimental conditions, which is considered an adequate result since no more than $10 \%$ of the drug should be released from a gastroresistant formulation in $2 \mathrm{~h}$ of experiment (USP, 2008). In addition, both results of gastroresistance (untableted and tableted microparticles) are statistically different $(p=0.0034)$.

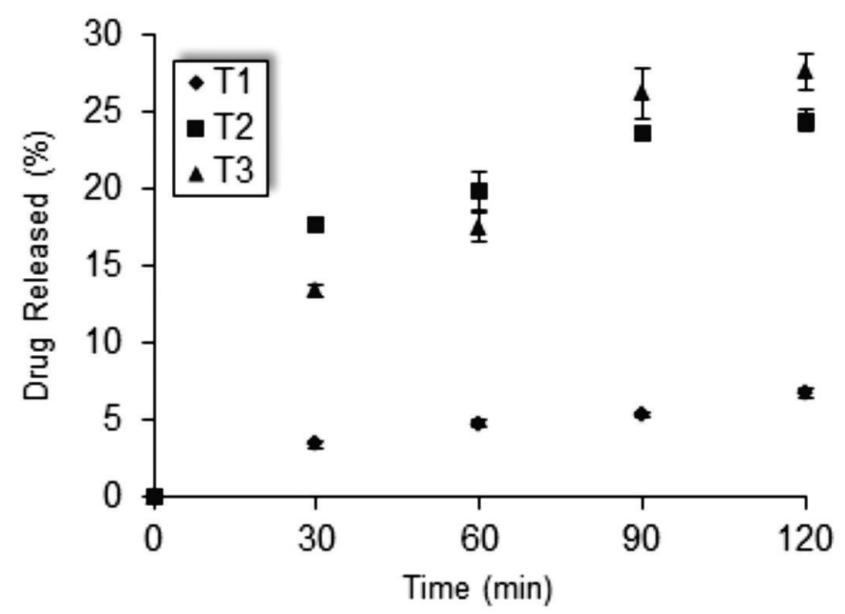

FIGURE 3 - In vitro release profiles of T1, T2 and T3 formulations in $0.1 \mathrm{~mol} / \mathrm{L} \mathrm{HCl} \mathrm{pH} 1.2$.

TABLE I - Properties of tableted microparticles

\begin{tabular}{lccc}
\hline & T1 & T2 & T3 \\
\hline Average weight (mg) & $758 \pm 13$ & $753 \pm 23$ & $750 \pm 13$ \\
Thickness (cm) & $0.4 \pm 0.0$ & $0.4 \pm 0.0$ & $0.4 \pm 0.0$ \\
Hardness (kgf) & $13.5 \pm 0.5$ & $8.0 \pm 0.5$ & $4.8 \pm 0.3$ \\
Uniformity of content (\%) & $99.0 \pm 0.5$ & $104.7 \pm 0.7$ & $103.2 \pm 2.7$ \\
\hline
\end{tabular}


Comparing the results obtained for untableted AMP(Cruz et al., 2010) and tableted AMP, only pullulan was capable of maintaining the gastroresistance of the microparticulate formulation, which could be explained by its ability to protect the particles against damage caused by the compression force. To corroborate this hypothesis, SEM analyzes of tablet cross-sections were performed. By comparing the photomicrograph of $\mathrm{T} 1$ tablet (Figure 4B) with that obtained for AMP (Figure 4A), it was possible to visualize the presence of individual particles with the same morphology observed in Figure 4A, which indicates that AMP remain intact after compression. On the other hand, tablets produced with microcrystalline cellulose and lactose showed few microparticles, suggesting that a great part of these structures has suffered rupture or fracture upon compression in samples T2 and T3 (Figure $4 C$ and 4D).

Tablets were also evaluated for their dissolution profiles in simulated intestinal fluid. In Figure 5 one may observe that the release profile of alendronate from pullulan tablets (T1) is significantly slower than T2 and T3 tablets $(\mathrm{p}<0.05)$. In the first hour, approximately $81 \%$ and $91 \%$ of alendronate were released from T2 and T3 formulations, respectively. On the other hand, 55\% of the drug was released from T1 tablets. This data is very similar to the result obtained for AMP in a previous study where $56 \%$ of alendronate was released from untableted AMP within the same time and under the same experimental conditions (Cruz et al., 2010). The similarity may be explained by the fact that microparticles tableted in the presence of pullulan remained intact and, hence, retained their release properties, which corroborates the gastroresistance result and SEM analysis. On the other hand, microcrystalline cellulose and lactose were not suitable for tableting AMP because the release properties were not the same observed for untableted AMP. Tablets containing multiples units should disintegrate into their subunits of release and drug release should not be affected by the compression. It is important to mention that all tablets disintegrated during the experiment.
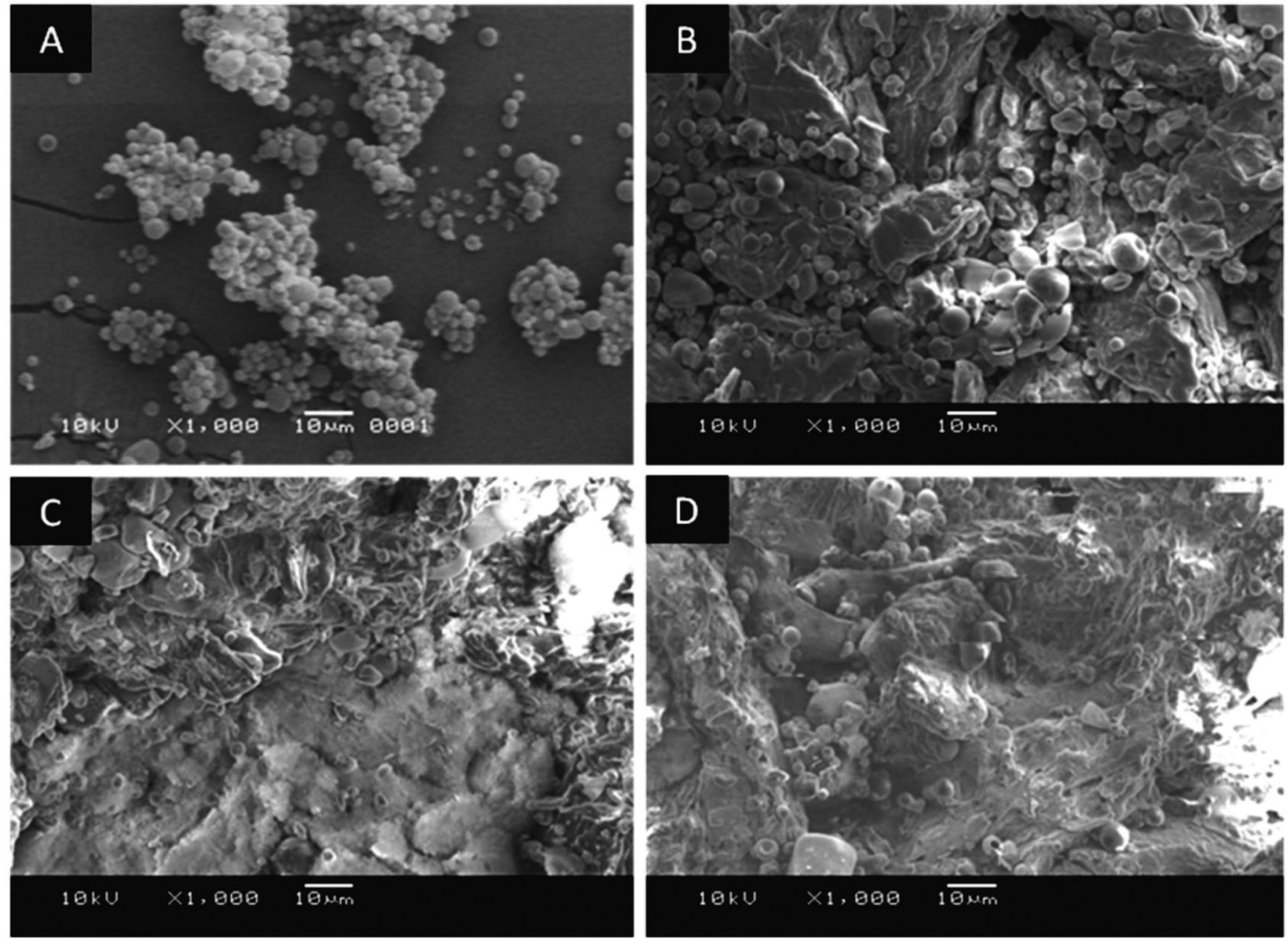

FIGURE 4 - SEM photomicrographs of microparticles (A) and cross-sections of tableted microparticles T1 (B), T2 (C) and T3 (D). 
TABLE II - Parameters derived from the mathematical modeling of alendronate release profile from tableted microparticles

\begin{tabular}{lccc}
\hline Model/Parameters & $\mathrm{T} 1$ & $\mathrm{~T} 2$ & $\mathrm{~T} 3$ \\
\hline First order & & & \\
$R$ & $0.9902 \pm 0.0008$ & $0.9886 \pm 0.0007$ & $0.9747 \pm 0.0030$ \\
$k\left(\mathrm{~min}^{-1}\right)$ & $0.0138 \pm 0.0002$ & $0.0303 \pm 0.0007$ & $0.0389 \pm 0.0016$ \\
$\mathrm{t}_{1 / 2}(\mathrm{~min})$ & 50.2 & 22.9 & 17.8 \\
\hline Korsmeyer-Peppas & $\mathrm{T} 1$ & $\mathrm{~T} 2$ & $\mathrm{~T} 3$ \\
\hline$R$ & $0.9949 \pm 0.0034$ & $0.9933 \pm 0.0015$ & $0.9882 \pm 0.0030$ \\
$A$ & $0.0175 \pm 0.0010$ & $0.1470 \pm 0.0080$ & $0.1810 \pm 0.0109$ \\
$N$ & $0.8415 \pm 0.0112$ & $0.3949 \pm 0.0105$ & $0.3647 \pm 0.0138$ \\
\hline
\end{tabular}

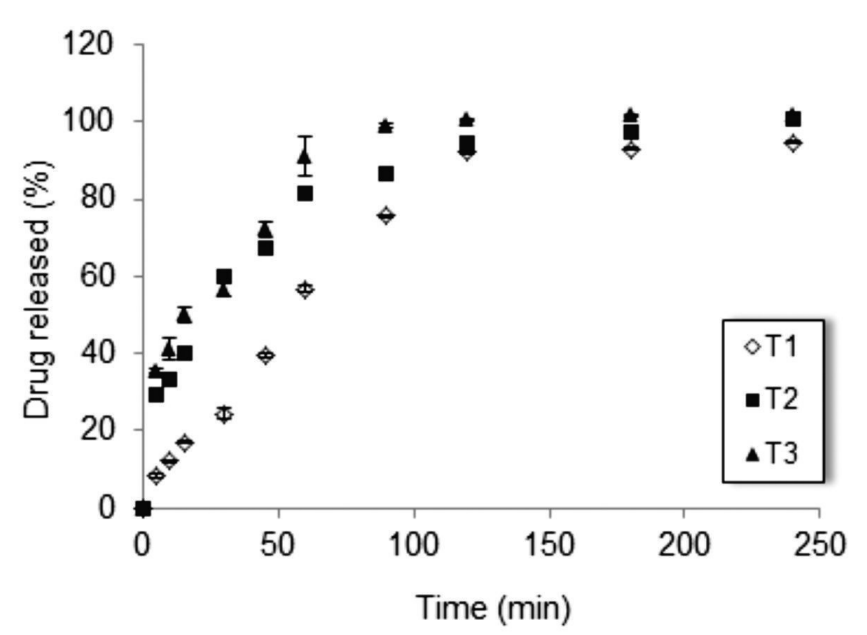

FIGURE 5 - Alendronate release profiles from T1, T2 and T3 tablets in phosphate buffer solution $\mathrm{pH}$ 6.8.

To calculate the rate constant associated to drug release, the dissolution data were fitted to first order equation. Table II shows that $\mathrm{T} 1$ tablets presented the lowest value of rate constant and, hence, the highest halflife, confirming the slower alendronate releases from this formulation. In addition, T1 tablets presents the best data fitting to the first order equation $(r>0.99)$.

The data were also fitted to the Korsmeyer-Peppas model in order to investigate the drug release mechanism. Taking into account the values obtained for the release exponent $n$, alendronate was released from pullulan tablets by anomalous transport, i.e., the drug release was dependent on the swelling of the system followed by drug diffusion. On the other hand, the Korsmeyer-Peppas model indicated Fickian diffusion as the main mechanism of alendronate release from $\mathrm{T} 2$ and $\mathrm{T} 3$ tablets. This result is consistent with the hypothesis that indicates rupture of the microparticles in T2 and T3 formulations because the swelling of the system did not occur in this case.

\section{CONCLUSION}

The results of this study suggest that pullulan is a useful excipient to prepare tableted microparticles, since it presented excellent filler-binder properties. T1 tablets exhibited superior technical qualities compared with the $\mathrm{T} 2$ and T3 formulations. The tablets manufactured with pullulan had good content uniformity, as well as thickness, low variation in average weight and suitable hardness with no addition of a specific binder. The compression of microparticles was found to not affect drug release, which indicates that the tablet behaves as a multiple unit dosage form. This may be due to the protective effect of pullulan and the rapid disintegration of the tablets into microparticles observed during the release study at $\mathrm{pH} 6.8$. The tableted microparticles prepared in this study have the potential to give a more predictable in vivo drug release and to decrease the gastrointestinal irritation caused by the oral administration of sodium alendronate. Tablets T1 have the potential to give a more predictable in vivo drug release and were considered a promising formulation for sodium alendronate oral administration.

\section{ACKNOWLEDGEMENTS}

The authors thank CNPq/Brazil and FIPE/UFSM/ Brazil Program for their financial support. In addition, they thank C.B. da Silva for providing access to spray drying.

\section{REFERENCES}

BECKERT, T. E.; LEHMANN, K.; SCHMIDT, P. C. Compression of enteric-coated pellets to disintegrating tablets. Int. J. Pharm., v.143, n.1, p.13-23, 1996.

BODMEIER, R. Tableting of coated pellets. Eur. J. Pharm. Biopharm., v.43, n.1, p.1-8, 1997. 
CHENG, K. C.; DEMIRCI, A.; CATCHMARK, J. M. Pullulan: biosynthesis, production, and applications. Appl. Microbiol. Biotechnol., v.92, n.1, p.29-44, 2011.

CRUZ, L.; ASSUMPÇÃO, E.; ANDRADE, S. F.; CONRADO, D. J.; GUTERRES, S. S.; POHLMANN, A. R. Microencapsulation of sodium alendronate reduces drug mucosal damage in rats. Drug Deliv., v.17, n.4, p.231-237, 2010 .

CRUZ, L.; ASSUMPÇÃO, E.; GUTERRES, S. S.; POHLMANN, A. R. High encapsulation efficiency of sodium alendronate in Eudragit S100/HPMC blend microparticles. Quím. Nova, v.32, n.5, p.1170-1174, 2009.

FREIBERG, S., ZHU, X. Polymer microspheres for controlled drug release. Int. J. Pharm., v.282, n.1/2, p.1-18, 2004.

HOLGADO, M. A.; CARABALLO, I.; ALVAREZ-FUENTES, J.; FERNANDEZ-HERVAS, M. J.; FERNANDEZAREVALO, M.; RABASCO, A. M. Influence of diluents and manufacturing method on the in vitro dissolution of carteolol hydrochloride matrix tablets. Int. J. Pharm., v.118, n.2, p.151-160, 1995.

JIVRAJ, M.; MARTINI, L. G.; THOMSON, C. M. An overview of the different excipients useful for the direct compression of tablets. Pharm. Sci. Technol., v.3, n.2, p.58-63, 2000.

KORSMEYER, R. W.; GURNY, R.; DOELKER, E.; BURI, P., PEPPAS, N. A. Mechanisms of solute release from porous hydrophilic polymers. Int. J. Pharm., v.15, n.1, p.25-35, 1983.

NGWULUKA, N. C.; IDIAKHOA, B. A.; NEP, E. I.; OGAJI, I.; OKAFOR, I. S. Formulation and evaluation of paracetamol tablets manufactured using the dried fruit of Phoenix dactylifera Linn as an excipient. Res. Pharm. Biotechnol., v.2, n.3, p.25-32, 2010.
PEZZINI, B. R.; SILVA, M. A. S.; FERRAZ, H. G. Formas farmacêuticas sólidas orais de liberação prolongada: sistemas monolíticos e multiparticulados. Rev. Bras. Cienc. Farm., v.43, n.4, p.491-502, 2007.

REKHA, M. R.; SHARMA, C. P. Pullulan as a promising biomaterial for biomedical applications: a perspective. Trends Biomater. Artif. Organs, v.20, 2007. Available in: <http://medind.nic.in/taa/t07/i1/taat07i1p116.pdf $>$. Accessed on: 2014 Jan. 12.

SINKA, I. C.; MOTAZEDIAN, F.; COCKS, A. C. F.; PITT, K. $\mathrm{G}$. The effect of processing parameters on pharmaceutical tablet properties. Powder Technol., v.189, n.2, p.276-284, 2009.

TORRADO, J. J.; AUGSBURGER, L. L. Effect of different excipients on the tableting of coated particles. Int. J. Pharm., v.106, n.2, p.149-155, 1994.

UNITED States Pharmacopeia: USP31; National Formulary: NF26. Rockville: The United States Pharmacopeial Convention, 2008.

VELASQUEZ, A. A.; MATTIAZZI, J.; FERREIRA, L. M.; POHLMANN, L.; SILVA, C. B.; ROLIM, C. M. B.; CRUZ, L. Risedronate-loaded Eudragit S100 ${ }^{\circledR}$ microparticles formulated into tablets. Pharm. Dev. Technol., v.19, n.3, p.263-268, 2014.

VARDE, N. K.; PACK, D. W. Microspheres for controlled release drug delivery. Expert Opin. Biol. Ther, v.4, n.1, p.35-51, 2004.

WENING, K.; BREITKREUTZ, J. Oral drug delivery in personalized medicine: unmet needs and novel approaches. Int. J. Pharm., v.404, n.1/2, p.1-9, 2011.

Received for publication on $13^{\text {th }}$ January 2014 Accepted for publication on $13^{\text {th }}$ September 2014 
